\title{
Epistemologia emancipatória de coletivos políticos
}

\author{
Emancipatory epistemology from political collectives \\ Epistemología emancipadora de colectivos políticos
}

Recebido em 29-08-2020

Modificado em 25-09-2020

Aceito para publicação em 12-10-2020

\section{Flavia de Faria}

Orcid: 0000-0001-5098-7673

Mestre em Ciências Sociais pela Universidade Paris V, doutoranda em Sociologia da Ecole des Hautes Etudes en Sciences Sociales, França, em duplo diploma com o Programa de Pós-Graduação em Antropologia Social da USP, Brasil. Bolsa de Pesquisa da EHESS/IIAC e IdA (França). Contato: defariaflavia@gmail.com

\section{Resumo}

Junho de 2013 é um ponto de inflexão para o surgimento acentuado de mobilizações que contribuem para uma ampla reconfiguração do ativismo social. Acreditamos que tal processo implica, por um lado, busca da horizontalidade, autonomia e participação. Por outro lado, a experimentação de outra forma de organização interna, de relações de poder e de tomada de decisões significa conceber, na prática e no quotidiano, um outro "espaço de aparecimento": tornar visíveis corpos dissidentes, reivindicar a legitimação e o reconhecimento de identidades e culturas historicamente subjugadas. Este artigo propõe analisar o conceito de "coletivos políticos" como sendo aqueles que atuam diretamente com as clivagens sociais.

Palavras-chave: Espaço de aparecimento; cultura autonomista; ativismo; coletivos 


\section{Introdução}

Junho de 2013 é um ponto de inflexão para o surgimento acentuado de mobilizações e ciclos de protesto político "a partir do qual um número crescente de coletivos e agrupamentos ativistas tem ocupado espaços públicos em várias cidades brasileiras” (Frúgoli Jr., 2018:77). Para Breno Bringel e Geoffrey Pleyers (2015:6), é preciso “(...) captar Junho não somente como um evento de protesto, mas como um processo aberto e inacabado, que inclui uma ampla reconfiguração do ativismo social". Acreditamos que tal processo implica configuração de um ativismo que privilegia a busca da horizontalidade, da tomada de decisões por consenso e de participação. Ou seja, junho de 2013 pode ser compreendido como um "momento" de evidenciação ou de maior destaque de coletivos e como um processo inacabado de reconfiguração do ativismo social, marcado tanto pela busca de repertórios autonomistas como por reivindicações de ocupação de espaços e por reconhecimento de identidades e culturas historicamente subjugadas.

Assim, por um lado, a experimentação de outra forma de organização interna, de relações de poder e de tomada de decisão significa, precisamente, conceber na prática e no quotidiano outro "espaço de aparecimento" (Arendt, 1983; Butler, 2018). Ou seja, a exigência de ocupar espaços públicos, de participar de momentos de decisão, de dar mais visibilidade a corpos dissidentes, de reivindicar a legitimação e o reconhecimento, por exemplo, da "amefricanidade" ${ }^{1}$, da transexualidade e de culturas periféricas. Configurar esse espaço de aparecimento significa forçar a presença de corpos negros, corpos de mulheres periféricas, de nativos, LGBTQ+, corpos violados e corpos ativistas em espaços historicamente limitados a outros grupos sociais. Espaços tais como os da tomada de decisão dentro de partidos, de universidades, de instituições e mesmo dentro de esferas hierárquicas de movimentos sociais (Gohn, 2017; 2019).

Por outro lado, o surgimento acentuado de coletivos após junho de 2013 reforça a rejeição de tais ativistas às formas tradicionais de organização de instituições e de partidos políticos. Isso revela o caráter antissistema dos coletivos derivados de junho, o que evidencia a ênfase do termo "ativista" em vez de "militante", já que este se refere à estruturas

\footnotetext{
${ }^{1}$ Retomando este conceito de Lélia Gonzalez (1988:77): "Por conseguinte, o termo amefricanas/americanos designa toda uma descendência: não só a dos africanos trazidos pelo tráfico negreiro, como a daqueles que chegaram à AMÉRICA muito antes de Colombo. Ontem como hoje, amefricanos oriundos dos mais diferentes países têm desempenhado um papel crucial na elaboração dessa Amefricanidade que identifica, na Diáspora, uma experiência histórica comum que exige ser devidamente conhecida e cuidadosamente pesquisada".
} 
historicamente imbricadas à partidos políticos e suas relações hierárquicas e centralizadas: "Coletivos autodenominam-se ativistas, e não como militantes de organizações, vivem experiências e experimentações que podem ser tópicas ou mais permanentes; fragmentadas ou mais articuladas" (Gohn, 2019:111). Em sentido próximo, Perez e Souza (2017:24) argumentam que os "Coletivos inventam nomes para distanciar suas práticas daquelas regidas por normas formais e hierárquicas", características tais atribuídas a algumas organizações de movimentos sociais institucionalizados ao longo das últimas décadas.

Forçar o espaço de aparecimento a corpos dissidentes e rejeitar o funcionamento hierárquico das instituições representam dois aspectos do "pé na porta da democracia"2 que coletivos políticos vêm enfatizando. A exigência de aparecimento e ocupação de espaços reflete a reivindicação por redistribuição e por reconhecimento. Essa demanda denuncia a subrepresentação nas instituições, partidos ou movimentos sociais assim como a hierarquia de gênero, racial, epistemológica, classista na organização interna de mobilizações e ações coletivas. Essa hierarquia é fortemente condenada por parte significativa de coletivos que trabalham para reduzir as múltiplas opressões ocasionadas por relações e modelos sociais hierarquizados.

Desse modo, este artigo sugere que tais reivindicações assumem a demanda de ocupar espaços de aparecimento organizados a partir de elementos autonomistas, pretendendo assim ajudar a compreender como operam coletivos que se destacam por sua atuação relacionada a "clivagens sociais" (tais como questões de gênero, classe, raça, sexualidade, etc.) ${ }^{3}$ denominados daqui em diante como "coletivos políticos". Para isso, a partir de uma revisão da literatura, este artigo propõe, em sua primeira parte, esmiuçar o conceito de "espaço de aparecimento" e, em seguida, relacioná-lo com elementos da cultura autonomista.

\section{Espaço de aparecimento}

$\mathrm{O}$ crescente surgimento de formas de organização social que se identificam como “coletivos” foi observado por vários autores após junho de 2013 (Gohn, 2014; 2017; 2019; Di

\footnotetext{
${ }^{2}$ Referência ao evento "\#Ocupa Política, pé na porta e amor pela democracia", organizado por coletivos de ocupação política como as Somos Muitas (de Belo Horizonte) e a Bancada Ativista (de São Paulo), de 7 à 10 de dezembro de 2017 na Ocupação Carolina Maria de Jesus, em Belo Horizonte. Para mais detalhes sobre coletivos de ocupação política, ver Faria $(2018 ; 2020)$.

${ }^{3}$ Estamos considerando, de acordo com o estudo de Perez e Souza (2017), a existência de dois grandes tipos de coletivos, a saber, aqueles que estão diretamente ligados a clivagens sociais e aqueles relacionados com as artes. A análise desses dois grandes tipos de coletivos pode ser encontrada em: Perez e Souza (2017), "Velhos, novos ou novíssimos movimentos sociais? As pautas e práticas dos coletivos". Anais do $41^{\circ}$ Encontro Anual da ANPOCS; Caxambú.
} 
Giovanni, 2015; Perez; Silva Filho, 2017; Frúgoli Jr., 2018; Perez, 2019; Pinheiro-Machado, 2019). Ainda que a existência de coletivos não seja um fenômeno novo, segundo o estudo de Perez (2019), a década de 2010 revela um notável aumento no surgimento desse tipo de grupos mobilizados. Tais dados convergem também com a intensificação de ativismos urbanos em diferentes tipos de ocupação e utilização das universidades, ruas, avenidas, praças, parques, portos, viadutos, colégios, etc. Ativismos que se mobilizam através de coletivos problematizando diferentes questões, em lugares distintos, com práticas variadas. Nesse sentido:

\begin{abstract}
Não há, portanto, um modelo único, há uma diversidade, multiplicidade de formas, temáticas, pautas e demandas, e campos de atuação, número de participantes, permanência ou duração no tempo histórico, formas de funcionamento/ operacionalização, suportes financeiros para atividades, apoios externos e relações com órgãos ou políticas institucionais [...] (Gohn, 2019:111).
\end{abstract}

Haveria, entretanto, característica comum diante dessa variedade de pautas e de práticas? A análise de Judith Butler (2018) sobre as manifestações do Occupy, ocorridas em 2011, poderia ajudar nesta reflexão. A autora revela como elemento transversal, diante da particularidade de cada mobilização, o espaço atribuído para a realização de assembleias públicas e abertas que, segundo a autora, atualizam o espaço de aparecimento de corpos dissidentes. Para Butler (2018), formas extraparlamentares de aliança e de apelo por justiça social se manifestam não apenas através da verbalização (do discurso, do palanque) mas pela performatividade corpórea de ocupar espaços politicamente negados à apropriação popular. Espaços cuja utilização é controlada por regras instituídas pelo poder público ou por instituições específicas, limitada a certas atividades além de restrita a determinados corpos. No confronto com regras, limites e restrições, corpos dissidentes reunidos, embora não representem a democracia em si, evocam momentos de profunda experiência política pois potencializam a soberania popular. "Corpos reunidos 'dizem' não somos descartáveis”, afirma a autora (Butler, 2018:276).

A partir de uma perspectiva arendtiana, Butler afirma que a ação política está diretamente ligada ao espaço de aparecimento público. Hannah Arendt (1983) argumentava que o privado está relacionado à intimidade, aos sentimentos, emoções e subjetividade enquanto que as atividades políticas, ao contrário, ao serem compartilhadas publicamente com outras pessoas, tornam-se realidades objetivas ${ }^{4}$. Butler propõe repensar o que significa o espaço de

\footnotetext{
4 "É a presença do outro vendo o que vemos, ouvindo o que ouvimos, que nos assegura a realidade do mundo e de nós mesmos (...) Nosso senso de realidade provém inteiramente da aparência e, portanto, da existência de um domínio público" (Arendt, 1983:90-91), tradução da autora.
} 
aparecimento acrescentando em sua reflexão o questionamento a respeito da dimensão corporal da ação política. Quais corpos aparecem no espaço público conceituado por Arendt? Quais atividades são legítimas para aparecer em público e quais se limitam à esfera privada?

Nesse sentido, Butler destaca que a reunião de corpos dissidentes em assembleia, em deliberação representa em si uma parte importante dos objetivos da ação coletiva. Isto é, o espaço de aparecimento não é apenas o meio material para a ação, mas é parte dela. Por isso, a ação política é também uma ação corporal, que impacta as fronteiras entre o público e o privado, o masculino e o feminino, o trabalho remunerado e o trabalho não remunerado. O gesto, a persistência, a expressão, a utilização quotidiana dos espaços promovem uma outra concepção de política, de público e de protesto.

[...] Quando corpos se juntam na rua, na praça ou em outras formas de espaço público (incluindo os virtuais), eles estão exercitando um direito plural e performativo de aparecer, um direito que afirma e instaura o corpo no meio do campo político e que, em sua função expressiva e significativa, transmite uma exigência corpórea por um conjunto mais suportável de condições econômicas, sociais e políticas, não mais afetada pelas formas induzidas de condição precária (Butler, 2018:165-171).

A exigência de ocupar espaços é em si uma ação direta de enfrentamento e também de aliança na construção de outra forma de fazer política. Está intimamente ligada com táticas do repertório autonomista e com demandas de reconhecimento de identidades pois, por um lado, implica outra forma de organização, de tomada de decisão, de distribuição e de participação numa busca por metodologias mais horizontais e, por outro lado, ao reconhecer a corporeidade da ação, confronta as regras, a moralidade e os modelos hierarquizados da colonialidade do poder e do saber (Quijano, 2005). Ou seja, das assimetrias raciais, epistemológicas, religiosas, de gênero, sexualidade, etc. confrontando assim o padrão normativo dos corpos (brancos, masculinos, heterosexistas, eurocêntricos) que historicamente aparecem no espaço público e político (Meneguello; Speck; Sacchet, 2012).

No período em que assistimos ao surgimento de centenas de coletivos no Brasil, entre 2013 e 2016, segundo Angela Alonso (2017), pode-se observar três repertórios de ação ${ }^{5}$ que marcaram as manifestações e os protestos. O primeiro repertório de confronto levantado por Alonso (2017) é o socialista, isto é, a identificação com a cor vermelha, o uso de megafones, carros de som, a presença de oradores e lideranças em palanques e suas bandeiras de partido em greves e protestos. O segundo é o repertório autonomista observado em espaços de

\footnotetext{
${ }^{5}$ Para Tarrow (2009) e Tilly (2012), repertório é uma articulação de rotinas de ação aprendidas e compartilhadas, ou seja, a forma como as pessoas agem juntas em busca de interesse compartilhado. É, portanto, a ação realizada por meio da deliberação coletiva.
} 
autogestão com organização descentralizada dos participantes, em uma relação que tende à horizontalidade e à tomada de decisão por consenso além da rejeição da representação como única forma de participação e a crítica da hierarquia. Esse repertório foi observado, segundo a autora, nas duas primeiras fases (eclosão do protesto e diversificação) das manifestações de junho de 2013, convocadas pelo Movimento Passe Livre (MPL). Por fim, o terceiro repertório é o patriota, caracterizado pelo culto ao nacionalismo, à ordem instituída e à retomada de símbolos da pátria como o hino e a bandeira brasileira.

Enfim, para Alonso (2017), os protestos de 2013 a 2016 revelam uma conexão com um desses diferentes repertórios. Neste caso, coletivos políticos que aproximam-se de instituições e rejeitam a reprodução de sua organização hierárquica (presidência, diretoria, coordenadoria, secretaria, etc.) e de seus espaços internos segregados confrontam modelos hierarquizados de gênero, de raça, sexualidade. Ao confrontar tais modelos, ressignificam o espaço de aparecimento, o sentido de espaço público e de política a partir da ocupação, por seus corpos, de espaços historicamente limitados e restritos a grupos sociais dominantes.

\section{Cultura autonomista, ativismo e coletivos}

O legado e o aprendizado dos jovens estudantes do MPL efetivamente colaboraram para a organização nos bastidores do ativismo (Dowbor; Szwako, 2013) através da visibilidade que atribuíram à cultura de ação autonomista. O que é uma cultura de ação autonomista? Resumiremos em cinco elementos: autonomia, ação performativa e prefigurativa, busca da horizontalidade interna, participação como método de tomada de decisão e crítica às instituições. Tais elementos estão presentes tanto na literatura que aborda ativismos pós junho de 2013, na qual o MPL aparece como um legado importante do repertório autonomista (Alonso, 2017) quanto na literatura que aborda coletivos.

A cultura autonomista reivindicada por coletivos revela, nesse contexto, o confronto com a forma tradicional de funcionamento de um partido político e de outras formas de mobilização no que se refere à organização e à destinação do espaço interno de tomada de decisão concedido diferentemente a uns e a outros, isto é, as hierarquias internas. Como destaca Perez (2019:584), “Ainda que pertencentes a partidos hierárquicos, os coletivos tentam se distanciar daquilo que consideram ultrapassado". Neste mesmo estudo, a autora observa que $33 \%$ dos coletivos analisados estão diretamente ligados a partidos políticos, mas ao afastaremse do que consideram ultrapassado, enfatizam mais o processo do que o resultado. Por isso, “importam menos as estruturas fixadas e mais as experiências criadoras, de modo que os 
movimentos estariam existindo mais na construção coletiva que circula por meio dos atores e práticas, do que nas organizações que formalizam" (Falchetti, 2017:18).

A ênfase no processo concentra-se, portanto, em ações corporais performativas no sentido levantado por Butler (2018): a dimensão corporal de ocupar e compartilhar espaços de aparecimento são parte da reivindicação em si. Durante uma ocupação, o processo de constituição de práticas cotidianas expressa uma experiência que problematiza a divisão do trabalho, a hierarquia de gênero, de classe e raça e expõe à esfera política e pública atividades de lazer, de cuidado, de diversão, de criatividade lúdica, etc. Para Geoffrey Pleyers (2016:111), a ação prefigurativa e performativa produz espaços de experiência.

\begin{abstract}
O ativismo é então prefigurativo (nas ações concretas prenuncia os elementos de um mundo melhor e mais democrático) e performativo (o objetivo não precede a ação, mas é concomitante com ela). Em vez de uma ruptura abrupta e radical que corresponde à ideia clássica de revolução, a transformação social é concebida como um processo. 'O outro mundo possível' não surgirá amanhã após a 'grande noite', começa aqui e agora nestes locais intersticiais [...] transformados em espaços de experiência alternativos e autônomos [...] (Pleyers, 2015:181).
\end{abstract}

Para Pleyers, na ação prefigurativa, o compromisso com a ressignificação das relações de poder deve aparecer tanto nas atividades coletivas como nas escolhas individuais: "o compromisso político não se limita à esfera 'política'. Requer uma atuação consistente frente aos valores não só nos protestos e ações políticos, mas também no cotidiano, na forma de consumir (ou não consumir), de se deslocar ou de se relacionar com os demais" (Pleyers, 2018:17). Para Pinheiro-Machado (2019:221), a ação prefigurativa enfatiza “o entendimento de que as lutas não podem reproduzir internamente as hierarquias que tentam combater. Os movimentos, assim, precisam ser um retrato da sociedade que querem construir".

No entanto, é óbvio que coletivos e ocupações não estão isentos de contradições e de conflitos. No artigo “As jornadas de junho e a questão de gênero", Sarmento, Reis e Mendonça descrevem várias situações em que as chamadas ocupações horizontais são atravessadas por práticas sexistas:

Se expressões de machismo fizeram-se presentes no percurso das ruas, elas também se tornaram evidentes nos espaços estruturados para a discussão da conjuntura política e das táticas de atuação e preparação de novos atos. Isso pode ser notado, por exemplo, nas APHs [Assembleia Popular Horizontal] que ocorriam em Belo Horizonte [...] (Sarmento; Reis; Mendonça, 2017:111).

Por isso, deveríamos considerar que os coletivos políticos e suas ocupações buscam a horizontalidade, ao contrário de afirmar que operam na total ausência de relações e de modelos 
opressivos. Trata-se de uma "reflexividade desconstrutivista" nas experiências cotidianas dos coletivos.

Para Perez (2019:587) “A adoção do nome 'coletivo' é uma resposta à descrença em relação à política parlamentar". O uso da denominação "coletivo" não é uma especificidade atual nem uma novidade, mas simboliza, durante a década de 2010-2020, uma forma de organização antissistema que defende a democracia radical com base na horizontalidade e na descentralização. Para Gohn (2019), a especificidade da expansão do surgimento de coletivos pós 2013 reflete a crise de representação, a desconfiança das instituições tradicionais (incluindo partidos, congressos, sindicatos). Nesse mesmo sentido, segundo Pinheiro-Machado (2019:213), os novíssimos movimentos sociais são todos antissistemas no sentido de que "são contra tudo o que está aî". É certo que o antissistema é uma característica presente em grande parte das mobilizações sociais de junho de 2013. O estudo de Tatagiba e Galvão (2019:86) sobre a evolução das principais queixas das manifestações ocorridas entre 2011 e 2016 corrobora tal afirmação ao mostrar que o tema "governo e sistema político" atingiu 12\% das demandas das manifestações ocorridas em 2011, seguido por 21\% em 2013, 42,4\% em 2015 e $60,2 \%$ em 2016.

Entretanto, é importante observar que algumas dessas mobilizações pós-2013 são contra o sistema no sentido de serem antipolíticas, ou seja, contra a instituição do Estado como promotor de direitos básicos e contra o próprio sentido de público. Outros, diferentemente, são contrários à política tradicional identificada com a sub-representação, o mecanismo de blindagem contra a sociedade (Nobre, 2013) e o exercício do personalismo (Faria, 2018).

Para Gohn (2017:338), tais elementos fortalecidos pelas jornadas de junho de 2013 possuem “(...) matrizes e fundamentos na corrente dos autonomistas, no anarquismo, nos libertários, no movimento Zapatista dos anos 1990 e na insatisfação com a esquerda tradicional". A corrente dos autonomistas refere-se em particular aos movimentos dos anos 1960 que irromperam em vários países contra as instituições e a ordem conservadora instituída: “O que maio de 68 e os outros movimentos dos anos 1960 mostraram foi a persistência e o poder da busca de autonomia, traduzida ao mesmo tempo pela recusa do mundo capitalistaburocrático e pelas novas ideias e práticas inventadas ou propagadas por esses movimentos" (Castoriadis, 2018:3040). A corrente autonomista rejeita a instituição tal como está instituída, é antiautoritária, libertária, anti-hierárquica, promove a participação, a ocupação de universidades e fábricas e a assembleia aberta (Castoriadis; Lefort; Morin, 2018). As décadas de 1960 e 1970 no Brasil também representam a efervescência dos movimentos contra o Estado autoritário, contra a instituição e a ordem militar, a ebulição das lutas de mulheres, do novo 
sindicalismo, de estudantes, dos movimentos de bairro e aqueles ligados à teoria da libertação que defendiam a construção de uma democracia a partir de baixo e à esquerda do espectro político.

Para Breno Bringel (2013), alguns dos ativismos oriundos de 2013 representam uma nova inflexão dos movimentos da década de 1970 que criticavam a centralização, a hierarquia, defendiam a autonomia, a democracia de base e exigiam direitos sociais de acesso à saúde, de urbanização de bairros periféricos, transporte público, condições de trabalho, etc. Com efeito, por um lado, coletivos que se inspiraram no repertório autonomista identificado com a atuação do MPL (Alonso, 2017) incorporam a cultura de ação autonomista, identificada há décadas pela teoria dos novos movimentos sociais ${ }^{6}$ e de suas reivindicações identitárias, libertárias e culturais (Castoriadis; Lefort; Morin, 2018; Touraine, 1978; Melucci, 1989) na luta por reconhecimento (Honneth, 2004).

O advento da teoria dos novos movimentos sociais (TNMS) já enfatizava, nos anos 70, as reivindicações culturais e criticava as teorias que colocavam ênfase na explicação racional e calculista dos movimentos sociais (ver Pleyers, 2008; Alonso, 2009). A busca pela autogestão dos novos movimentos sociais deslocava os mecanismos de dominação da pauta central dos movimentos. No Brasil, os “novos atores” das décadas de 1970 e 1980 são descritos na obra de Eder Sader (1988), porém, a intenção de deslocar a pauta da dominação parece ser um ambição pouco realista para quem se propõe a debater a interseccionalidade das opressões (Gonzalez, 1984) e assimetrias sociais que caracterizam o processo de urbanização brasileiro (Kowarick, 2000; 2013).

Assim, a crítica da modernidade e do capitalismo não parece apontar na TNMS e nos autonomistas o debate decolonial nem a perspectiva interseccional das opressões, que, por sua vez, encontram lugar privilegiado em coletivos políticos contemporâneos ao reivindicarem identidades e culturas historicamente desprezadas ou oprimidas pelos modelos sociais hierarquizados (Carvalho, 2018; Facchini et al., 2020; Mesquita, 2008). É por isso que, por outro lado, em paralelo à crítica ao modo de organização vertical e assimetria dos espaços de aparecimento interno de movimentos e partidos, a interseccionalidade e a decolonialidade são

\footnotetext{
${ }^{6}$ A teoria dos novos movimentos sociais surge a partir de 1968, endossada por Alain Touraine, para identificar o que ele considera o surgimento da "sociedade pós-industrial". Ele observa a descentralização do papel do movimento operário, que desempenhou um papel central nas lutas sociais até então. Ao criticar a lógica dos sistemas econômicos (marxismo e liberalismo) e dos sistemas sociais (estruturalismo e funcionalismo), Touraine $(1978 ; 1984 ; 1992)$ enfatiza a subjetividade e a historicidade ao invés dos processos de dominação, reprodução e de biopoder. Os novos atores sociais (mulheres, negros, ambientalistas, indígenas, estudantes) reivindicam o direito de escolher seu modo de vida, a gestão e a produção do cotidiano a despeito apenas das reivindicações "materialistas" organizadas em torno da divisão do trabalho e da redistribuição.
} 
fortemente mobilizadas por coletivos feministas, queer, negros, culturais periféricos, LGBTQ+, estudantis, etc. Ultrapassando o referencial teórico da TNMS e dos autonomistas, coletivos políticos enfatizam a incompatibilidade de um projeto de libertação e reconhecimento cultural que não problematize a assimetria da distribuição (de recursos, de direitos sociais, de oportunidades, etc.), isto é, os diferentes tipos de colonialidades e de opressão.

Mas isso não significa que se trata de um "novo fenômeno sociológico". A dupla reivindicação por reconhecimento (de identidades e culturas) e por redistribuição (material), associada com a crítica decolonial, também é observada em movimentos que os precedem. Para Pleyers (2018), a emergência do movimento Zapatista, em 1994, sinaliza uma etapa para a sociologia dos movimentos sociais que não se enquadra na "nova" ou "velha" tipologia. Movimentos antiglobalização problematizam o capitalismo ao mesmo tempo em que reivindicam identidade, estilo de vida alternativo à globalização e o bien-vivir.

\footnotetext{
Mesmo que assumam várias lutas e reivindicações, tanto o movimento antiglobalização quanto os movimentos da década atual diferem em pontos chaves dos "novos movimentos sociais" dos anos 1970 e 1980. Enquanto estes últimos se mobilizaram em torno de demandas culturais (...), os atores contemporâneos também têm insistido nas demandas econômicas e redistributivas. O que os caracteriza é a combinação de reivindicações "materialistas" e "pós-materialistas" (Pleyers, 2018:29).
}

O movimento Zapatista fortalece as lutas anticapitalistas e inspira a organização do movimento antiglobalização muito comprometido com as questões ambientais, anticoloniais e democráticas (Pleyers, 2010). O levante antiglobalização na América Latina também foi fortemente apoiado por ecofeminismos indígenas que confrontam a colonialidade do poder e do saber (Santos, 2013; Segato, 2015; Martínez Andrade, 2019). Movimentos e coletivos antiglobalização e anticapitalistas são nomeados por Pleyers (2018:16) como "alter-ativismo". Trata-se de ativismos que:

Por sua vez, valorizam e defendem a experiência vivida frente aos poderes do capital e do consumismo e, portanto, consideram a mudança como um processo de experimentações criativas onde os atores tentam implantar seus valores de horizontalidade, igualdade e criatividade em atos concretos e "prefiguram" outros mundos possíveis (ibid::17).

Pleyers (2018:16) sugere que o alter-ativismo foi o impulso para a "onda global de movimentos que emergiu em todos os continentes na segunda década do século 21 ”. Assim, a geração alter-ativista se expressa, segundo o autor, por meio das alternativas de transformação cotidiana (do modo de consumir, de pensar, de fazer coincidir a ação ao discurso, de se relacionar com os outros) e, ao mesmo tempo, no espaço público por meio das ocupações, da 
construção de espaços de experiência onde relações e princípios convergem com reivindicações anticapitalistas e contra a lógica neoliberal, produzindo outra relação com a cidade, com a terra, com o trabalho e a produção.

Por fim, elementos da cultura autonomista - observados tanto em alter-ativismos e coletivos contemporâneos quanto em movimentos anteriores - junto com demandas de ocupação de espaços públicos e políticos por corpos historicamente oprimidos parecem compor o contexto histórico, político e social no qual se observa a emergência acentuada de coletivos políticos. Atuando diretamente contra as assimetrias sociais, coletivos políticos são identificados tanto por elementos da cultura autonomista (como a busca de horizontalidade e crítica antissistema) como por reivindicações de reconhecimento de corpos negros, nativos, feministas, LGBTQ+, periféricos como corpos políticos que reivindicam seu espaço de aparecimento e de participação.

\section{Breve conclusão}

Este artigo teve como objetivo contribuir para os estudos sobre ativismos contemporâneos, em especial os coletivos políticos. Como nos mostram os autores Perez e Silva Filho (2017), faltam referenciais teóricos e estudos em relação à ampliação acentuada de coletivos como expressão de ativismo. No mesmo sentido, Gohn (2019:114) afirma que “[...] o termo 'coletivo' necessita de pesquisa, debates e discussões teóricas”. A reflexão acerca de coletivos políticos pretende colaborar para o debate sobre como operam coletivos que estão diretamente ligados à clivagens sociais. A partir da tentativa de identificar a ocupação de espaços (assembleias, ruas, escolas, parques, partidos, instituições, etc.) como ação política em si, refletimos acerca do esvaziamento dos termos "novos" ou "velhos", mostrando que reivindicações similares precedem a existência de coletivos políticos contemporâneos.

Nesse sentido, a forma de organização política chamada "coletivos" reprova, por um lado, a existência de relações hierárquicas entre a base e o topo da pirâmide militante, entre os representantes e os representados, entre os intelectuais e os operacionais. Essa crítica é ainda mais enfatizada quando empenham-se em denunciar as opressões e se comprometem em não reproduzi-las uns com os outros em seus espaços internos. Por outro lado, coletivos experimentam a luta dos corpos dissidentes em ocupar espaços públicos de aparecimento (Butler, 2018) e em reforçar e ampliar políticas afirmativas contra o racismo, androcentrismo, a homofobia, o heterosexismo, eurocentrismo existentes em instituições, partidos e até mesmo em mobilizações ditas horizontais. 
Trata-se de evidenciar tanto as estruturas opressoras até mesmo dentro de organizações que supostamente lutam pela justiça social quanto trazer à luz o reconhecimento das diversas subjetividades pautado em processos de decolonialidades (política, identitária, cultural, epistemológica, etc.). Enfim, ao exigirem redistribuição e reconhecimento, acesso a espaços de aparecimento e, consequentemente, participação na tomada de decisão de diferentes instâncias, coletivos políticos promovem o "pé na porta" da democracia brasileira.

\section{Referências}

ALONSO, Angela (2017), "A Política das ruas: protestos em São Paulo de Dilma à Temer”. Novos estudos Cebrap Especial, São Paulo, pp. 49-58 [Consult. 01-05-2018]. Disponível em http://novosestudos.uol.com.br/wp-content/uploads/2018/07/Angela-Alonso_A-pol\%C3\%ADticadas-ruas.pdf (2009), "As teorias dos movimentos sociais: um balanço do debate". Revista Lua Nova, $\mathrm{n}$. 76, pp. 49-86. Disponível em http://www.scielo.br/scielo.php?script=sci_arttext\&pid=S010264452009000100003\&lng=pt\&tlng=pt . [Consult. 24-06-2017].

ARENDT, Hannah (1983), Condition de l'homme moderne. Calmann Lévy.

BRINGEL, Breno (2013), "Miopias, sentidos e tendências do levante brasileiro de 2013". Insight Inteligência, n. 62 , pp. $42-54$ [Consult. 19-08-2016]. Disponível em https://www.academia.edu/8526539/_2013_Miopias_sentidos_e_tend\%C3\%AAncias_do_levante_ brasileiro_de_2013

BRINGEL, Breno; PLEYERS, Geoffrey (2015), "Junho de 2013... dois anos depois Polarização, impactos e reconfiguração do ativismo no Brasil". Nueva Sociedad especial em português, v. 30, n. 88, pp. 4-17 [Consult. 15-03-2017].

Disponível em https://rosa.ehess.fr/service/home/ /?auth=co\&loc=fr_FR\&id=2561\&part=3

BUTLER, Judith (2018), Corpos em aliança e a política das ruas: Notas sobre uma teoria performativa de assembleia. Civilização Brasileira. Versão e-book Kindle.

CARVALHO, Mario F. de L. (2018), "Notas etnográficas sobre duas manifestações de rua do ativismo trans no Brasil”. Revista Brasileira de Ciências Sociais, v. 33, n. 9 [Consult. 13-05-2019]. Disponível em: $\quad$ http://www.scielo.br/scielo.php?script=sci_abstract\&pid=S0102$69092018000100512 \& \operatorname{lng}=e n \& n r m=i s o \& \operatorname{lng}=p t$

CASTORIADIS, Cornelius (2018), "Os movimentos dos Anos Sessenta", In: Cornelius Castoriadis, Claude Lefort e Edgar Morin, Maio de 68: A brecha. Autonomia Literária. Versão e-book Kindle.

CASTORIADIS, Cornelius, LEFORT, Claude; MORIN, Edgar (2018), Maio de 68: A brecha. Autonomia Literária. Versão e-book Kindle.

CERTEAU, Michel de (1990), L'invention du quotidien - 1. Arts de faire. Paris, Gallimard.

DAVIS, Angela Yvone (1983), Mulheres, raça e classe. São Paulo, Boitempo.

DI GIOVANNI, Julia R. (2015), "Artes de abrir espaço. Apontamentos para a análise de práticas em trânsito entre arte e ativismo". Cadernos de Arte e Antropologia, v. 4, n. 2, pp. 13-27 [Consult. 1407-2018]. Disponível em http://journals.openedition.org/cadernosaa/911 
DOWBOR Monika; SZWAKO José (2013), "Respeitável público...: performance e organização dos movimentos antes dos protestos de 2013". Novos estudos Cebrap, n. 97, pp. 43-55 [Consult. 09-012020]. Disponível em http://www.scielo.br/scielo.php?script=sci_abstract\&pid=S0101$33002013000300004 \& \operatorname{lng}=$ en\&nrm=iso\&tlng=pt

FACCHINI, Regina, CARMO, Íris N.; LIMA, Stephanie P. (2020), "Movimentos feminista, negro e LGBTI no Brasil: sujeitos, teias e enquadramentos", Educação \& Sociedade, v. 41 [Consult. 09-092020]. Disponível em:

http://www.scielo.br/scielo.php?script=sci_arttext\&pid=S0101-73302020000100205\&tlng=pt

FALCHETTI, Cristhiane (2017), "Da Institucionalização da Participação à Emergência do Autonomismo: Tendências recentes da ação coletiva no Brasil". Lasa - Congresso f the Latin American Studies Association. Lima, Peru.

FARIA, Flávia de (2018), "Participação, renovação e ocupação: limites da representação e experiências de transformação política na cidade de São Paulo". Revista Contraponto, v. 5, n. 1. [Consult. 29-032019]. Disponível em http://seer.ufrgs.br/contraponto/article/view/85468

. (2020), "Ativismo, instituição e repertório autonomista: uma etnografia sobre coletivos políticos". Revista Brasileira de Sociologia, v. 8, n. 20, pp. 177-198 [Consult. 15-12-2020]. Disponível em

http://www.sbsociologia.com.br/rbsociologia/index.php/rbs/article/view/rbs.741/pdf_741

FRÚGOLI JR, Heitor (2018), “Ativismos urbanos em São Paulo”. Revista Caderno CRH, v. 31,

n. 82, pp. 75-86 [Consult. 09-11-2019].

Disponível em https://www.scielo.br/pdf/ccrh/v31n82/0103-4979-ccrh-31-82-0075.pdf

GOHN, Maria da G. (2019), Participação e democracia no Brasil. Petrópolis, Editora Vozes. . (2017), Manifestações e protestos no Brasil: correntes e contracorrentes na atualidade. São Paulo, Cortez Editora (coleção "Questões da nossa época: Sociologia”). Versão e-book Kindle. . (2014), Manifestações de junho de 2013 no Brasil e praças dos indignados no mundo. Petrópolis, Editora Vozes. Versão e-book Kindle.

GONZALEZ, Lélia (1988), “A categoria político-cultural de amefricanidade”. Revista Brasileiro, Rio de Janeiro, 92/93, pp. 69-82 [Consult. 09-12-2019].

Disponível em https://negrasoulblog.files.wordpress.com/2016/04/a-categoria-polc3adtico-culturalde-amefricanidade-lelia-gonzales1.pdf

HILL COLLINS, Patricia (2019), Pensamento feminista negro. São Paulo, Boitempo.

HOLlANDA, Heloisa Buarque de (2019), Pensamento Feminista: conceitos fundamentais. Bazar do Tempo.

HONNETH, Axel (2004), "La théorie de la reconnaissance: une esquisse". Revue du MAUSS, v. 23, n. 1, pp. 133 [Consult. 09-07-2017]. Disponível em http://www.cairn.info/revue-du-mauss-2004-1page-133.htm

KOWARICK, Lúcio (2013), "Cortiços: a humilhação e a subalternidade". Revista Tempo Social, novembro, volume 25, n. 2, pp. 49-77 [Consult. 06-04-2018]. Disponível em https://www.scielo.br/pdf/ts/v25n2/a04v25n2.pdf . (2000), Escritos urbanos. São Paulo, Editora 34.

MAIA, Gretha L. (2013), "A juventude e os coletivos: como se articulam novas formas de expressão política", Revista Eletrônica do Curso de Direito da UFSM, v. 8, n. 1 [Consult. 13-02-2020]. Disponível em http://periodicos.ufsm.br/revistadireito/article/view/8630 
MARTÍNEZ ANDRADE, Luis (2019), Feminismos a la contra: entre-vistas al Sur Global, Santander, La Vorágine.

MELUCCI, Alberto (1989), “Um objetivo para os movimentos sociais?”. Revista Lua Nova, n. 17, pp. 49-66 [Consult. 25-07-2019]. Disponível em https://www.scielo.br/pdf/ln/n17/a04n17.pdf

MENEGUELLO, Rachel, MANO, Maíra K.; GORSKI, Caroline (2012), “Alguns condicionantes do déficit representativo de mulheres e negros na política", in Mulheres e negros na política: estudo exploratório sobre o desempenho eleitoral em quatro estados brasileiros. Campinas, Centro de Estudos de Opinião Pública, Universidade Estadual de Campinas.

MESQUITA, Marcos R. (2008), "Cultura e política: A experiência dos coletivos de cultura no movimento estudantil". Revista Crítica de Ciências Sociais, n. 81, pp. 179-207 [Consult. 09-102019]. Disponível em http://journals.openedition.org/rccs/660

NOBRE, Marcos (2013), Choque de democracia: Razões da revolta. Companhia das Letras.

PEREZ, Olivia C. (2019), "Relações entre coletivos com as Jornadas de Junho". Opinião Pública, v. 25, n. 3, pp. 577-596 [Consult. 04-04-2020].

Disponível em https://www.cesop.unicamp.br/por/opiniao_publica/artigo/636

PEREZ, Olivia C. e SOUZA, Bruno M. (2017), "Velhos, novos ou novíssimos movimentos sociais? As pautas e práticas dos coletivos", in Anais do $41^{\circ}$ Encontro Anual da ANPOCS; Caxambú.

PEREZ, Olivia e SILVA FILHO, Alberto Luís (2017), "Coletivos: um balanço da literatura sobre as novas formas de mobilização da sociedade civil". LATITUDE, v. 11, n. 01, pp. 255-294 [Consult. 09-11-2019]. Disponível em http://www.seer.ufal.br/index.php/latitude/article/view/2812

PINHEIRO-MACHADO, Rosana (2019), Amanhã vai ser maior: O que aconteceu com o Brasil e possiveis rotas de fuga para a crise atual. São Paulo, Planeta do Brasil. Versão e-book Kindle.

PLEYERS, Geoffrey (2018), Movimientos sociales en el siglo XXI: perspectivas y herramientas analíticas. Buenos Aires, CLACSO (Colección Democracias en Movimiento).

. (2016), "Engagement et relation à soi chez les jeunes alteractivistes". Agora débats/jeunesses, v. 72, n. 1 [Consult. 02-01-2019]. Disponível em http://www.cairn.info/revue-agora-debatsjeunesses-2016-1-page-107.htm

. (2015), "Volverse actor: dos vías para los movimientos sociales en el siglo XXI". Revista de Estudios Sociales, n. 35, pp. 179-183 [Consult. 09-07-2019]. Disponível em http://revistas.uniandes.edu.co/doi/full/10.7440/res54.2015.13

. (2010), Alter-globalization: becoming actors in the global age. Cambridge, Polity.

(2008), "Chapitre 3. Sociologie de l'action et enjeux sociétaux chez Alain Touraine", In: Épistémologie de la sociologie. De Boeck Supérieur, pp. 69-86.

QUIJANO, Aníbal (2013), "Colonialidade do poder e classificação social”, In: Boaventura de Sousa Santos (Org), Epistemologias do sul. São Paulo, Cortez Editora.

SADER, Eder (1988), Quando novos personagens entram em cena - experiências e, falas e lutas dos trabalhadores da Grande São Paulo (1970-80). Rio de Janeiro, Paz e Terra.

SANTOS, Boaventura S (2013), Epistemologias do sul. São Paulo, Cortez Editora.

SARMENTO, Rayza; REIS, Stephanie; MENDONÇA, Ricardo F. (2017), “As Jornadas de Junho no Brasil e a questão de gênero: as idas e vindas das lutas por justiça". Revista Brasileira de Ciência Política, n. 22, pp. 93-128 [Consult. 09-05-2018]. Disponível em https://www.scielo.br/pdf/rbcpol/n22/2178-4884-rbcpol-22-00093.pdf 
SEGATO, Rita L. (2015), La crítica de la colonialidad en ocho ensayos: y una antropología por demanda. Buenos Aires, Argentina, Prometeo Libros.

TARROW, Sidney (2009), O poder em movimento: movimentos sociais e confronto político. Petrópolis, Vozes.

TATAGIBA, Luciana e GALVÃO, Andreia (2019), "Os protestos no Brasil em tempos de crise (20112016)". Opinião Pública, v. 25, n. 1, pp. 63-96 [Consult. 09-01-2020]. Disponível em https://www.scielo.br/pdf/op/v25n1/1807-0191-op-25-1-0063.pdf

TILLY, Charles (2012), "Movimentos sociais como política". Revista Brasileira de Ciência Política, n. 3, pp. 133-160 [Consult. 15-07-2019].

Disponível em http://periodicos.unb.br/index.php/rbcp/article/view/6562

TOURAINE, Alain (1992), Critique de la modernité. Paris, Fayard. . (1984), Le retour de l'acteur: essai de sociologie. Paris, Fayard (Coleção "Mouvements"). . (1978), La voix et le regard. Paris, Seuil.

VERGÈS, Françoise (2020), Um feminismo decolonial. Ubu Editoras. 


\begin{abstract}
June 2013 is a turning point for the sharp increase in the mobilizations that contributed to a broad reconfiguration of social activism. This process implies, on the one hand, the search for horizontality, autonomy, and participation. On the other hand, experimenting with another form of internal organization, power relations, and decision-making allows, in practice and daily life, another "space of appearance": to make dissident bodies visible, claiming legitimation and recognition of historically subjugated identities and cultures. This article proposes to analyze the concept of "political collectives" as those that act directly with social cleavages.
\end{abstract}

Keywords: Space of appearance; autonomism; activism; collective.

\title{
Resumen
}

Junio de 2013 es un punto clave para el fuerte aumento de las movilizaciones que contribuyen a una amplia reconfiguración del activismo social. Creemos que tal proceso implica, la búsqueda de la horizontalidad, la autonomía y la participación, por un lado. Y, por otro lado, experimentar con otra forma de organización interna, relaciones de poder y toma de decisiones. Lo que significa concebir, en la práctica y en la vida cotidiana, otro "espacio de aparición": visibilizar los cuerpos disidentes, reivindicar la legitimación y reconocimiento de identidades y culturas históricamente subyugadas. Este artículo propone analizar el concepto de "colectivos políticos" como aquellos que actúan directamente con las asimetrías sociales.

Palavras clave: Espacio de aparición; autonomismo; activismo; colectivo. 